\title{
PREVALENCE OF KNEE BUCKLING AMONG GRADE 3 OSTEOARTHRITIS PATIENTS OF KNEE: A SELF-REPORTED STUDY
}

\author{
DHEERAJ LAMBA ${ }^{1 *}$, RITAMBHARA K UPADHYAY ${ }^{2}$
}

${ }^{1}$ Department of Physiotherapy, Jimma University, Jimma, Ethiopia. ${ }^{2}$ Division of Academic Affairs, Lovely Professional University, Phagwara, Punjab, India. Email: dheeraj.lamba@gmail.com

Received: 28 September 2017, Revised and Accepted: 13 April 2018

\section{ABSTRACT}

Objective: The present study aims to find out the sensation and frequency of episodes of knee buckling in Grade 3 osteoarthritis (OA) and its physiotherapy treatment.

Methods: Experimental study design is used to determine the knee buckling in Grade 3 OA of the knee joint. Subjects are classified into two groups. Subjects with Grade 3 OA knee are examined for knee buckling. The investigator used a questionnaire to collect data from filed documents. Data were numerically coded and captured in excel, using SPSS 20 version software. Descriptive statistics were applied to analyze the data.

Results: The study has provided baseline information about knee buckling among Grade 3 OA knee. In Group A, out of 32 study projects, 25 reported a sensation of knee buckling and reported no history of knee buckling in previous 3 months. Among 25 subjects reported knee buckling, the frequency of episodes of knee buckling reported $>5$ in 15 subjects while 3-5 in 6 and 1-2 in 4 subjects were reported in previous 3 months. In Group B, after completion of 3 weeks of knee stabilizing exercise, 10 subjects reported no sensation of buckling out of 25 subjects in past 3 weeks, while remaining 9 subjects were reported 1-2 and 6 subjects were reported only 3-5 number of episodes of buckling.

Conclusion: The study shows that knee stabilizing and balancing exercises are helpful in reducing or preventing knee buckling.

Keywords: Knee buckling, Osteoarthritis of knee, Quadriceps and hamstring muscles.

(C) 2018 The Authors. Published by Innovare Academic Sciences Pvt Ltd. This is an open access article under the CC BY license (http://creativecommons. org/licenses/by/4. 0/) DOI: http://dx.doi.org/10.22159/ajpcr.2018.v11i7.22814

\section{INTRODUCTION}

Knee buckling is associated with patients suffering from osteoarthritis $(\mathrm{OA})$ of the knee. It is characterized by the loss of postural support across the knee at the time of weight bearing while standing or walking. This self-supported knee instability is often associated with shifting, the sensation of buckling or even giving away of the knee [1]. This has been reported in nearly $60-80 \%$ of patients struggling with knee OA [2-6]. There is more severe activity limitation among patients with knee OA plus knee instability as compared to those without this sensation. In addition, there are higher rates of falling, higher pain levels, and alteration in walking patterns [3,5-13] in persons with knee instability and also the reason behind the onset of knee OA and progression [7-14] although the exact cause of the knee instability is to be identified. In fact, knee-buckling is a multifactorial problem characterized by biomechanical impairments, for instance, muscle weakness, high laxity, impaired proprioceptive accuracy. These symptoms are commonly found in the patients with knee $\mathrm{OA}$, and they have been hypothesized in many instances from time to time as an important causal factor in self-supported knee instability [1,2,4-6,13-18]. The quadriceps and hamstring muscles are vital for providing stability to the knee joint by acting as shock absorbers and distributing the knee-joint load. Nevertheless, the proprioceptive receptors are also said to be imperative for preventing excessive and possible injurious movements of the knee as they act as the precursors of alterations in position, movements of the knee joint and posture $[10,17]$. Laxity or the inadequate passive restraint of the knee has also been hypothesized to be the cause of knee instability during functional and dynamic activities [15,17]

Robust lower extremity muscles are suggested to be the structures aiding in the stabilization of the knee, even under circumstances when there is impairment of the proprioceptive accuracy or high rate of laxity $[4,5,11,12,15,16]$. In patients with impaired or debilitated proprioceptive accuracy or high laxity, the muscle strength is more strongly related to activity limitations as compared to patients with adequate proprioceptive accuracy or low laxity was shown in a study conducted by Van der Esh et al. [17]. The authors also suggested that strong muscles around the knee can compensate for the impaired proprioceptive accuracy or high laxity to maintain knee stability and eventually accounting for less severe activity limitations.

\section{METHODS}

The experimental study design was used to determine the knee buckling in Grade $3 \mathrm{OA}$ of the knee joint. Patients were classified into two groups, subjects with Grade $3 \mathrm{OA}$ knee to examine fine knee buckling based on the questionnaire was controlled group and those given physiotherapy as the experimental group. The physiotherapy treatment was given for 3 weeks. Data were collected from Uni Hospital and Physiotherapy Outpatient Department (OPD), Lovely Professional University. A questionnaire to collect data from filed documents was used. Data were numerically coded and captured in excel, using SPSS 20 version software. Descriptive statistics were used to analyze the data.

\section{Risk factors of $\mathrm{OA}$}

Growing age is one of the primary OA risk factors. OA is the most common joint disease prevalent worldwide. It is also one of the most common causes of pain and disability in older people. Statistics suggest that one-third of people over 65 years of age suffer from knee arthritis. $70 \%$ of people have evidence of $\mathrm{OA}$. OA is more prevalent among men before the age of 50 years than women. Women are more likely to suffer from $\mathrm{OA}$ than men after the age of 50 years. 
Some of the other factors known OA risk factors are obesity or excessive weight, injury, hormones, congenital or developmental deformities, certain deformities, weak thigh muscles, genetic factors, race, certain occupations, and other diseases which change cartilage structure, low intake of Vitamin C and D. It has been found that obese people are 4-5 times more likely to suffer from OA compared to people of normal weight.

\section{Sampling}

Samples collected by convenience sampling procedure.

\section{CRITERIA FOR SELECTION}

Subject for the study was selected based on the inclusion and exclusion criteria. The inclusion criteria include age between 40 and 80 years, both male and females, medically diagnosed Grade 3 knee OA patient by an orthopedic surgeon, years of knee OA to 53 . The exclusion criteria included prior knee injury or surgery, Grades 1 and $2 \mathrm{OA}$, and other orthopedic conditions such as ankylosing spondylitis and septic arthritis (Fig. 1).

Table 1: Age distribution of participants

\begin{tabular}{ll}
\hline Participants & Frequency (\%) \\
\hline $40-49$ & $7(17.50)$ \\
$50-59$ & $19(47.50)$ \\
$60-69$ & $12(30.00)$ \\
$70-79$ & $2(5.00)$ \\
Grand total & $40(100.00)$ \\
\hline
\end{tabular}

Table 2: Gender distribution

\begin{tabular}{ll}
\hline Participants & Count of sex (\%) \\
\hline F & $29(72.50)$ \\
M & $11(27.50)$ \\
Grand total & $40(100.00)$ \\
\hline
\end{tabular}

\section{RESULTS}

Data analysis and results

Self-reported knee buckling in Grade 3 OA patients.

\section{DISCUSSION}

The study has provided a baseline of information about the kneebuckling among Grade 3 OA knee patients. The age group distribution of participants as depicted (Table 1), 7 participants fall in the age group of 40-49, 19 in the age group of 50-59, 12 in the age group of $60-69$, and 2 subjects in $70-80$ age group. 29 females and 11 males participated in the study (Table 2). In Group A, out of 40 study projects, 30 reported the sensation of knee buckling and reported no history of knee buckling in the previous 3 months (Table 3). Among 40 subjects who reported knee buckling, the frequency of episodes of knee buckling in previous 3 months between 0 and 4 was reported in 5 subjects, while 5-9 in 27 subjects and 10-15 in 8 subjects (Table 4). In Group B, after completion of 3 weeks of knee stabilizing exercise, 10 subjects reported no sensation of buckling out of 40 subjects in past 3 weeks, while out of the remaining 30 subjects, 17 reported $0-1$ episodes of buckling, 11 subjects showed 2-3 episodes, and 2 showed $4-5$ episodes of buckling in the past 3 weeks (Table 5). Out of 40 participants, 10 showed no involvement of knee buckling, 13 showed bilateral involvement, 8 subjects showed left knee involvement, and 9 showed right knee involvement (Table 6). Mean, median, mode, and standard deviation and p-value for age, height, weight, body mass index, years of OA knee, and number of episodes of buckling after 3 weeks of exercise can be correlated (Tables 7 and 8).

In this community-based study, we found that knee-buckling is commonly found in people with Grade 3 knee $\mathrm{OA}$ and they complained of limitations in walking, climbing stairs, and physical function. With the progression of $\mathrm{OA}$ with age, the symptoms knee buckling would aggravate with time if timely intervention not provided [10].

Table 3: Sensation of buckling in the past 3 months (Group A)

\begin{tabular}{lll}
\hline $\begin{array}{l}\text { Sensation of years of } \\
\text { buckling in past } \mathbf{3} \text { months }\end{array}$ & $\begin{array}{l}\text { Count of sensation of episodes of } \\
\text { buckling in past 3 months (Group A) }\end{array}$ & $\begin{array}{l}\text { Percentage of sensation of episodes } \\
\text { of buckling in past } \mathbf{3} \text { months (\%) }\end{array}$ \\
\hline No & 10 & 25.00 \\
Yes & 30 & 75.00 \\
Grand total & 40 & 100.00 \\
\hline
\end{tabular}

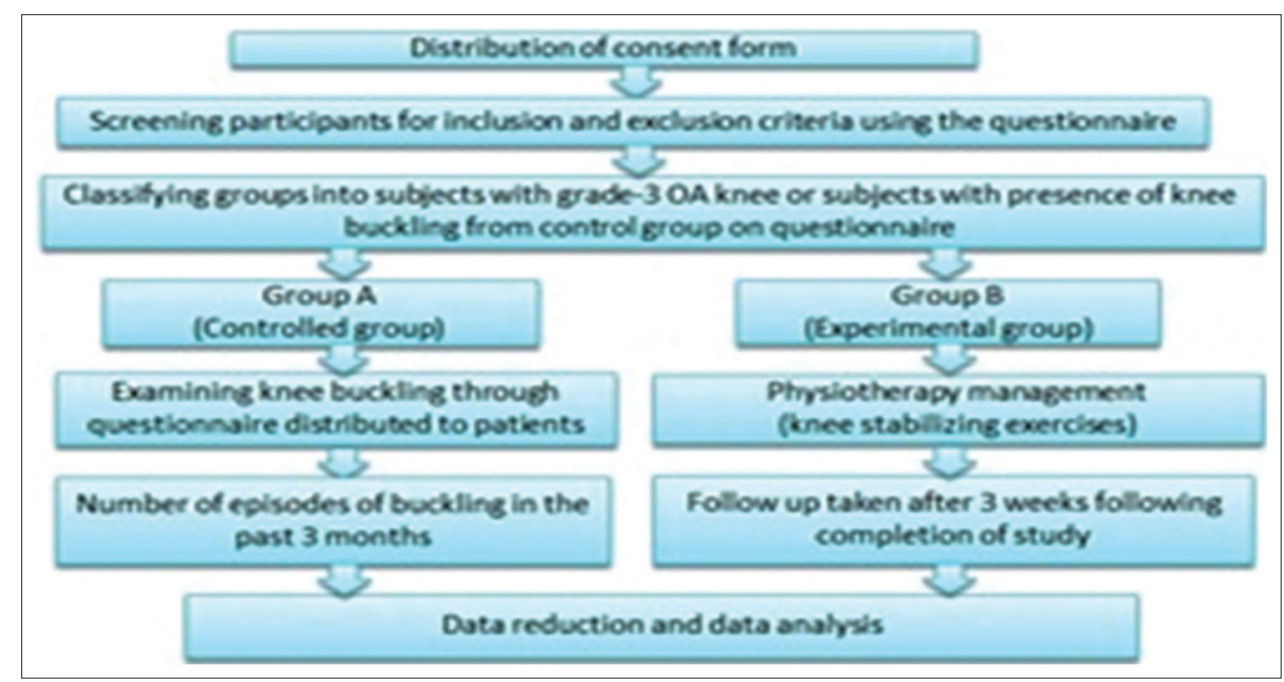

Fig. 1: Methodology 
People are benefitted from the advancement of the medical sciences with the improvements in medications, imaging, and surgical techniques and equipment as doctors can more effectively diagnose and treat the illnesses. Despite, all these advancements in the medical field, $\mathrm{OA}$ is the most common form of arthritis, and the pain associated with it is the prime cause of functional disability, inactivity or activity limitation, and reduced health-related quality of life. OA is a multi-factorial disease involving systemic factors (age, sex, genetics, hormones, and nutritional factors), intrinsic joint vulnerability (bridging muscle weakness, previous damage, laxity, and mal-alignment), and extrinsic factors acting on joints (obesity and specific injurious activities). OA (Grade $3 \mathrm{OA}$ ) of the knee is a major cause of knee buckling among the aging population of the industrialized world. The study dealt with the frequency of knee buckling in the previous 3 months among patients visiting with the knee instability to find out whether new buckling was associated with particular characteristics such as muscular weakness or knee or other joint pain. Finally, the sensation and the number of the sensation of knee buckling in Grade $3 \mathrm{OA}$ of knee and its related physiotherapy treatment was examined [18-21].

Table 4: Years of OA knee

\begin{tabular}{ll}
\hline Count of No. of years of $\mathbf{O A}$ & Participants (\%) \\
\hline $0-4$ & $5(12.50)$ \\
$5-9$ & $27(67.50)$ \\
$10-15$ & $8(20.00)$ \\
Grand total & $40(100.00)$ \\
\hline
\end{tabular}

OA: Osteoarthritis

\section{CONCLUSION}

The study demonstrated that sensation and frequency of episodes of knee buckling are very common in Grade 3 OA knee patients. However, knee stabilizing exercise is highly significantly effective in preventing or reducing the number of episodes of knee buckling. It is important to develop research-based evidence of physiotherapy practice. Physiotherapist's practice is evidence based in all aspects of health care. There are a few studies on knee buckling in OA of the knee. This study could not cover all the aspects of the vast area. Hence, it is recommended that the next generation of physiotherapy members should continue study regarding this area; this may involve the use of large-scale sample size and participants from different states of the country.

\section{ETHICAL APPROVAL}

Ethical approval was taken from the Department of Physiotherapy, Lovely Professional University.

\section{ACKNOWLEDGMENTS}

We are thankful to Jimma University, Ethiopia, and Lovely Professional University, Uni Hospital, Department of Physiotherapy OPD, Phagwara, Punjab, and its staff and OPD of Physiotherapy, Uni Hospital, Lovely Professional University, Phagwara, Punjab, for helping in carrying out this research to a fruitful outcome.

\section{CONFLICTS OF INTEREST}

There are no conflicts of interest of any sort.

Table 5: Number of episodes of buckling after completion of 3 weeks of exercise

\begin{tabular}{lll}
\hline $\begin{array}{l}\text { No. of episode of } \\
\text { buckling }\end{array}$ & $\begin{array}{l}\text { Count of No. of episode of buckling after 3 weeks of } \\
\text { exercise (Group B) }\end{array}$ & $\begin{array}{l}\text { Percentage of episode of buckling after 3 weeks of } \\
\text { exercise (Group B) (\%) }\end{array}$ \\
\hline 0 & 10 & 25.00 \\
$0-1$ & 17 & 42.50 \\
$2-3$ & 11 & 27.50 \\
$4-5$ & 2 & 5.00 \\
Grand total & 40 & 100.00 \\
\hline
\end{tabular}

Table 6: Extremity involvement of lower limb

\begin{tabular}{lll}
\hline Involvement of knee buckling & Count of EPISODE of knee side & Count of episode of knee side (\%) \\
& & 25.00 \\
None & 10 & 32.50 \\
B/L & 13 & 20.00 \\
Lt & 8 & 22.50 \\
Rt & 9 & 100.00 \\
Grand total & 40 & 100 \\
\hline
\end{tabular}

Table 7: Statistics

\begin{tabular}{|c|c|c|c|c|c|c|c|}
\hline Parameters & Age & Height & Weight & BMI & $\begin{array}{l}\text { Years of } \\
\text { OA knee }\end{array}$ & $\begin{array}{l}\text { No. of episodes } \\
\text { of buckling }\end{array}$ & $\begin{array}{l}\text { No. of episodes of buckling } \\
\text { after } 3 \text { weeks of exercise }\end{array}$ \\
\hline \multicolumn{8}{|l|}{$\mathrm{N}$} \\
\hline Valid & 40 & 40 & 40 & 40 & 40 & 30 & 30 \\
\hline Missing & 0 & 0 & 0 & 0 & 0 & 10 & 10 \\
\hline Mean & 56.65 & 5.397 & 72.963 & 28.205 & 7.30 & 7.60 & 1.40 \\
\hline Median & 57.00 & 5.350 & 72.600 & 27.600 & 7.00 & 7.00 & 1.00 \\
\hline Mode & 59 & 5.4 & $68.6^{a}$ & 25.0 & 6 & $8^{a}$ & 0 \\
\hline SD & 7.322 & 0.2904 & 7.8242 & 3.9365 & 2.719 & 5.223 & 1.354 \\
\hline Minimum & 43 & 5.0 & 60.2 & 21.0 & 3 & 1 & 0 \\
\hline Maximum & 74 & 6.0 & 89.2 & 40.0 & 14 & 25 & 5 \\
\hline
\end{tabular}

${ }^{a}$ Multiple modes exist. The smallest value is shown. BMI: Body mass index, OA: Osteoarthritis, SD: Standard deviation 
Table 8: Correlations

\begin{tabular}{|c|c|c|c|c|c|c|c|}
\hline Parameters & Age & Height & Weight & BMI & Year & Buckling A & After 3 weeks B \\
\hline \multicolumn{8}{|l|}{ Age } \\
\hline Pearson correlation & 1 & 0.022 & 0.264 & -0.026 & 0.002 & -0.134 & -0.090 \\
\hline Significant (2-tailed) & & 0.890 & 0.099 & 0.873 & 0.992 & 0.482 & 0.636 \\
\hline $\mathrm{N}$ & 40 & 40 & 40 & 40 & 40 & 30 & 30 \\
\hline \multicolumn{8}{|l|}{ Height } \\
\hline Pearson correlation & 0.022 & 1 & $0.528^{* *}$ & -0.144 & -0.057 & $-0.402^{*}$ & -0.307 \\
\hline Significant (2-tailed) & 0.890 & & 0.000 & 0.377 & 0.725 & 0.028 & 0.098 \\
\hline $\mathrm{N}$ & 40 & 40 & 40 & 40 & 40 & 30 & 30 \\
\hline \multicolumn{8}{|l|}{ Weight } \\
\hline Pearson correlation & 0.264 & $0.528^{* *}$ & 1 & -0.051 & -0.146 & -0.246 & -0.057 \\
\hline Significant (2-tailed) & 0.099 & 0.000 & & 0.757 & 0.369 & 0.190 & 0.764 \\
\hline $\mathrm{N}$ & 40 & 40 & 40 & 40 & 40 & 30 & 30 \\
\hline \multicolumn{8}{|l|}{ BMI } \\
\hline Pearson Correlation & -0.026 & -0.144 & -0.051 & 1 & -0.160 & 0.071 & 0.114 \\
\hline Significant (2-tailed) & 0.873 & 0.377 & 0.757 & & 0.324 & 0.708 & 0.550 \\
\hline $\mathrm{N}$ & 40 & 40 & 40 & 40 & 40 & 30 & 30 \\
\hline \multicolumn{8}{|l|}{ Year } \\
\hline Pearson correlation & 0.002 & -0.057 & -0.146 & -0.160 & 1 & -0.103 & -0.208 \\
\hline Significant (2-tailed) & 0.992 & 0.725 & 0.369 & 0.324 & & 0.587 & 0.270 \\
\hline $\mathrm{N}$ & 40 & 40 & 40 & 40 & 40 & 30 & 30 \\
\hline \multicolumn{8}{|l|}{ Buckling A } \\
\hline Pearson correlation & -0.134 & $-0.402^{*}$ & -0.246 & 0.071 & -0.103 & 1 & $0.940^{* *}$ \\
\hline Significant (2-tailed) & 0.482 & 0.028 & 0.190 & 0.708 & 0.587 & & 0.000 \\
\hline $\mathrm{N}$ & 30 & 30 & 30 & 30 & 30 & 30 & 30 \\
\hline \multicolumn{8}{|l|}{ After 3 weeks B } \\
\hline Pearson correlation & -0.090 & -0.307 & -0.057 & 0.114 & -0.208 & $0.940^{* *}$ & 1 \\
\hline Significant (2-tailed) & 0.636 & 0.098 & 0.764 & 0.550 & 0.270 & 0.000 & \\
\hline $\mathrm{N}$ & 30 & 30 & 30 & 30 & 30 & 30 & 30 \\
\hline
\end{tabular}

${ }^{* *}$ Correlation is significant at the 0.01 level (2-tailed). ${ }^{*}$ Correlation is significant at the 0.05 level (2-tailed). BMI: Body mass index

\section{REFERENCES}

1. Felson DT, Niu J, McClennan C, Sack B, Aliabadi P, Hunter D, et al. Knee buckling: Prevalence, risk factors and associated limitations in function. Ann Intern Med 2007;147:534-40.

2. Fitzgerald GK, Piva SR, Irrgang JJ. Reports of joint instability in knee osteoarthiritis: Its prevalence and relationship to physical function. Arthritis Rheum 2004;51:941-6.

3. Ramsey DK, Snyder-Mackler L, Lewak M, Newcomb W, Rudolph KS. Effect of anatomic alignment on muscle function during gait in patients with medical compartment knee osteoarthritis. Arthritisheum 2007;57:389-97.

4. Schmitt LC, Fitzgerald GK, Reisman AS, Rudolph KS. Instability, laxity and physical function in patients with medical knee osteoarthritis. Physical Ther 2008;88:1506-16.

5. Lewek MD, Rudolph KS, Synder-Mackler L. Control of frontal plane knee laxity during gait in patients with medical compartment knee osteoarthritis. Osteoarthritis Cartilage 2004;12:745-51.

6. Barker K, Lamb SE, Toye F, Jackson S, Barrington S. Association between radiographic joint space narrowing, function, pain and muscle power in severe osteoarthritis of the knee. Clin Rehabil 2004:18:793-800.

7. Schipplein OD, Andraiacchi TP. Interaction between active and passive knee stabilizers during level walking. J Orthop Res 1991;9:113-9.

8. Hubley-Kozey CL, Deluzio KJ, Landry SC, McNutt JS, Stanish WD. Neuromuscular alteration ensuring walking in persons with moderate knee osteoarthritis. J Electromyogr Kinesiol 2006;16:365-78.

9. Rutherford DJ, Hubley-Kozey CL, Stanish WD, Dunbar MJ. Neuromuscular alterations exist with knee osteoarthritis presence and severity despite walking velocity similarities. Clin Biomech (Bristol, Avon) 2011;26:377-83

10. Jackson BD, Wluka AE, Teichtahl AJ, Morris ME, Cicuttini FM.
Reviewing knee osteoarthritis: A biomechanical perspective. J Sci Med Sport 2004:7:347-57.

11. Mikesky AE, Meyer A, Thompson KL. Relationship between quadriceps strength and rate of loading during gait in women. J Orthop Res 2000;18:171-5.

12. Barrett DS, Cobb AG, Bentley G. Joint proprioception in normal, osteoarthritic, and replaced knees. J Bone Joint Surg Br 1991;73:53-6.

13. Magee DJ. Orthopaedic Physical Assessment. $3^{\text {rd }}$ ed. Philadelphia: W.B. Saunders Company; 1997.

14. Moore KL, Dalley AF. Clinically Oriented Anatomy. $5^{\text {th }}$ ed. USA: Lippincott Williams \& Wilkins; 2006

15. Sharma L, Lou C, Felson DT, Dunlop DD, Kirwan-Mellis G, Hayes KW, et al. Laxity in healthy and osteoarthritic knees. Arthritis Rheum 1991;42:861-70.

16. Schmitt LC, Rudolph KS. Muscle stabilization strategies in people with medical knee osteoarthritis: The effect of instability. J Orthop Res 2008;26:1180-5

17. Van der Esh M, Steultjens M, Knol DL, Dinant H, Dekker J. Joint laxity and the relationship between muscle strength and functional ability in patients with osteoarthritis of the knee. Arthritis Rheum 2006;55:953-9.

18. Segal NA, Glass NA, Felson DT, Hurley M, Yang M, Nevitt M, et al. The effect of quadriceps strength and proprioception on risk for knee osteoarthritis. Med Sci Sports Exerc 2010;42:2081-8.

19. Hortobagyi T, Westerkamp L, Beam S, Moody J, Garry J, Holbert D, et al. Altered hamstring quadriceps muscle balance in patients with knee osteoarthritis. Clin Biomech (Bristol, Avon) 2005;20:97-104

20. Oka Dwicandra NM. Prayitno Setiadi AA. Comparison of pain score in osteoarthritis patients treated with a combination of diacerein and meloxicam and meloxicam alone. Int J Pharm Pharm Sci 2017;9:69-73.

21. Ali SH, Kassim AA. Relationship between undercarboxylated osteocalcin and osteoprotegerin in knee osteoarthritis. Int J Pharm Pharm Sci 2014;6:344-6. 